\title{
Antioxidant Variability of Propolis Collected from Different Zones in Hives
}

\author{
Samet Okuyan ${ }^{1, *}\left(\mathbb{D}\right.$, Serdar Mehmetoğlu ${ }^{1}\left(D\right.$, Neslihan Çakıcı $^{1}(\mathbb{C})$ \\ ${ }^{1}$ Apiculture Research Institute, Ordu, Turkey
}

\section{Article History \\ Received 28 April 2020 \\ Accepted 28 July 2020 \\ First Online 31 July 2020}

\section{*Corresponding Author \\ Tel.: +905367157359 \\ E-mail: \\ samet.okuyan@tarimorman.gov.tr}

\section{Keywords}

Total phenolic content

DPPH

FRAP

\begin{abstract}
Propolis is biologically highly active honey bee product. The popularity of propolis is increasingly growing because of its contribution to human health. Propolis composition is highly variable depending on its sources. Different honey bees subspecies can collect propolis having different anti-bacterial effect. Honey bees, collect propolis for a couple of different purposes such as narrowing the entrance of their own hives and airflow isolation. In this study, propolis collected from entrances (EC) and top of deep supper (FC) of six different hives, and the antioxidant properties of these propolis samples were compared. Average values of total phenolic content were 68.5 and $62.6 \mathrm{mg} \mathrm{GAE} / \mathrm{g}$ propolis extract, $\mathrm{IC}_{50}$ value of DPPH were 0.14 and 0.16 $\mathrm{mg} / \mathrm{mL}$, and FRAP value were 43.5 and $38.4 \mathrm{mg} \mathrm{TE} / \mathrm{g}$ propolis extract samples collected from EC and FC, respectively. Statistically significant differences have not been found in terms of antioxidant activity analysis between EC and FC collected propolis $(P>0.05)$.
\end{abstract}

\section{Introduction}

Propolis (bee glue) is collected from variable plant sources and the name came from the Greek, pro-for or in defence, and polis- the city, and means is defence of the city (or the hive) (Ghisalberti, 1979). Propolis is used by bees for versatile purposes such as covering holes and cracks, repairing combs, sticking the border combs, narrowing the entrance of the hive for easy defending, and embalming the aliens (Ghisalberti, 1979). The composition of propolis is highly variable depending on collected sources, and the most important botanical propolis sources are poplars (Populus spp.), briches (Betula spp.), willows (Salix spp.), chestnut tree (Aesculus hippocastanum L.), elms (Ulmus spp.), pine trees (Pinus spp.), oaks (Quercus spp.), spruces (Picea spp.) and ashes (Fraxinus spp.) (Bonvehí \& Coll, 1994; Greenaway, Scaysbrook, \& Whatley, 1990). Marcucci
(1995) and Bankova, Christov, Kujumgiev, Marcucci, and Popov (1995) identified that propolis have more than 300 constitutes. It is reported that-variable biological activities of the ethanolic extract of propolis such as hepatoprotective effect (González et al., 1994), antitumor activity (Mitamura et al., 1996), antioxidative activity (Matsushige, Kusumoto, Yamamoto, Kadota, \& Namba, 1995), antimicrobial activity (Bankova et al., 1995), and anti-inflammatory effect (Krol et al., 1996).

Honey bees accumulate propolis to entrances of their hives for narrowing, to top of deep supper the hives for air isolation, between the combs for sticking the combs, and some more hive region. There are various research indicate that the composition of propolis not only be affected from environmental and botanical origin factors and this can be affected from the race of bees and bees diseases as well (Popova, Antonova, \& Bankova, 2017; Silici \& Kutluca, 2005). 
Honey bees can consciously prefer to choose the different resource of propolis in nature. Bees accumulate propolis to the entrance of hive for narrowing the entrance and maybe grooming themselves with propolis,

but bees accumulate propolis to top of deep supper for airflow isolation. Hypothesis of this study is that the antioxidant effect of propolis collected from the entrance of the hive and top of deep supper the hives can be different due to bees collect this propolis for different purposes.

\section{Materials and Methods}

Propolis collected from 6 colonies in Apicultural Research Institute apiary. The raw propolis were collected from two different zones in hives; the entrance (EC) of the hives and the top of deep supper the hives (FC). Collected raw propolis extracted by using $70 \%$ ethanol solution. Samples placed to erlenmeyer flasks and ethanol solutions were added. Propolis/solvent ratio was 3:10 (m/V). Maceration lasted 7 days at room temperature. Samples were filtered through the filter page after maceration and were held at 4 으 for one day. Samples were filtered again with filter page, then ethanol vaporized at the rotary evaporator. Thus, extracted propolis obtained.

\section{Extraction of propolis samples}

$0.1 \mathrm{~g}$ from each propolis sample weighed and ethanol added up to $10 \mathrm{~mL}$ in falcon tubes. Samples left at $4^{\circ} \mathrm{C}$ for one day, then all samples centrifuged $10 \mathrm{~min}$ at $5000 \mathrm{rpm}$. The supernatant was used for antioxidant analysis (Elmastas, Isildak, Turkekul, \& Temur, 2006; Lachman, Orsak, Hejtmankova, \& Kovarova, 2010).

\section{Determination free radical scavenging activity (DPPH)}

Trolox was used as standard for free radical scavenging activity analysis and activity was determined by reading absorbances of compounds at $517 \mathrm{~nm}$ which reacted with 1,1-diphenyl-2-picryl-hydrazil (DPPH). $3 \mathrm{~mL}$ ethanol and $1 \mathrm{~mL}$ DPPH were added to $80 \mu \mathrm{L}$ sample solution. All absorbances obtained after holding of all samples at room temperature for 30 minutes (Shimada, Fujikawa, Yahara, \& Nakamura, 1992).

\section{Determination Total Phenolic Content (TPC)}

$200 \mu \mathrm{L}$ from supernatants of each sample were transferred to tubes. $0.1 \mathrm{~mL}$ Folin-Cicoalteu reactive and $0.3 \mathrm{~mL} 2 \% \mathrm{Na}_{2} \mathrm{CO}_{3}$ solution added and all tubes filled up to $5 \mathrm{~mL}$ with distilled water. A standard curve obtained by reaction of gallic acid with Folin-Cicoalteu. Absorbances of samples were read at $760 \mathrm{~nm}$ and results were calculated as $\mathrm{mg} \mathrm{GAE} / \mathrm{g}$ propolis extract (Gülçin, Şat, Beydemir, Elmastaş, \& Küfrevioğlu, 2004; Slinkard \& Singleton, 1977).
Determination ferric reducing ability of plasma (FRAP)

$80 \mu \mathrm{L}$ samples were transferred to tubes for determining FRAP value of each sample and $1.25 \mathrm{~mL}$ sodium phosphate buffer $(0.2 \mathrm{M}, \mathrm{pH} 6.6)$ and $1.25 \mathrm{~mL}$ $1 \%$ potassium ferro cyanide solution were added, and solutions left for incubation at $50^{\circ} \mathrm{C}$ for 30 minutes. 1.25 $\mathrm{mL} 10 \% 3$-chloro acetic acid solution and $0.25 \mathrm{~mL} 1 \%$ $\mathrm{FeCl}_{3}$ solution were added after incubation. Trolox was used to obtain standard curve and all samples read at $700 \mathrm{~nm}$ at spectrophotometer (Oyaizu, 1986).

\section{Statistical Analysis}

IBM SPSS Statistics 20 program was used for statistical analysis. Kruskal Wallis $\mathrm{h}$ test was used to compare mean ranks of all values of 2 groups.

\section{Results}

The value of total phenolic content of propolis extract between 47.9 and $88.1 \mathrm{mg}$ GAE/g propolis extract showed in Table 1. Even though the propolis were collected from different zones of the hive, there are no statistical differences between the groups $(P>0.05)$. The result of DPPH was expresed $I C_{50}$ values that ranged between $0.12-0.19 \mathrm{mg} / \mathrm{mL}$ and while average value for propolis EC collected was $0.14 \mathrm{mg} / \mathrm{mL}$, average value for propolis FC collected was $0.16 \mathrm{mg} / \mathrm{mL}$. $\mathrm{IC}_{50}$ values of all samples can be seen in Table 1 . DPPH values of propolis samples collected from different areas of hives were not different statistically $(P>0.05)$. FRAP values ranged between 32.9-58.9 mg TE/g propolis extract and average values propolis samples EC and FC collected were 43.5 and $38.4 \mathrm{mg} \mathrm{TE} / \mathrm{g}$ propolis extract respectively. FRAP values of samples were also indifferent statistically $(P>0.05)$.

\section{Discussion}

\section{Free Radical Scavenging Activity Analysis (DPPH)}

$\mathrm{IC}_{50}$ value of DPPH analysis expresses the concentration of antioxidant compound which required for scavenging $50 \%$ of free radicals found in medium. Marghitas, Dezmirean, Moise, Mihai, and Laslo (2009) obtained $\mathrm{IC}_{50}$ values between $0.3-5.6 \mathrm{mg} / \mathrm{mL}$ in the study which propolis samples collected from Romanian. Mercan et al. (2006) indicate that $I C_{50}$ value range from 3.4 to $4.6 \mathrm{mg} / \mathrm{mL}$. I $1 C_{50}$ values calculated in this study were lower in contrast with values of these works. Talla et al. (2017) compare DPPH value of Cameroonian propolis and vitamin $\mathrm{C}$. The $\mathrm{IC}_{50}$ value of Cameroonian is found $0.30 \mathrm{mg} / \mathrm{mL}$. That value is higher than our findings. The possible explanation of this nonoverlapping is that our propolis sample were collected Black See region of Turkey, but Talla et al. (2017)'s study propolis samples were collected from Cameroon. 
Table 1. The TPC, DPPH and FRAP analysis results of propolis collected from FC and EC.

\begin{tabular}{lcll}
\hline Samples & TPC & DPPH $\left(I C_{50}\right)$ & FRAP \\
\hline FC1 & $57.0 \pm 3.76$ & $0.17 \pm 0.03$ & $33.3 \pm 2.45$ \\
FC2 & $60.0 \pm 2.60$ & $0.13 \pm 0.04$ & $37.9 \pm 2.52$ \\
FC3 & $54.0 \pm 3.21$ & $0.13 \pm 0.03$ & $36.2 \pm 1.60$ \\
FC4 & $68.2 \pm 4.05$ & $0.19 \pm 0.04$ & $34.0 \pm 1.04$ \\
FC5 & $64.8 \pm 3.33$ & $0.17 \pm 0.02$ & $43.6 \pm 3.23$ \\
FC6 & $71.4 \pm 5.49$ & $0.14 \pm 0.04$ & $45.5 \pm 3.21$ \\
Avg. & $62.6 \pm 2.51$ & $0.16 \pm 0.01$ & $38.4 \pm 1.24$ \\
Min. & $54.0 \pm 2.21$ & $0.13 \pm 0.03$ & $33.3 \pm 2.45$ \\
Max. & $71.4 \pm 5.49$ & $0.19 \pm 0.04$ & $45.5 \pm 3.21$ \\
\hline EC1 & $76.8 \pm 3.18$ & $0.17 \pm 0.03$ & $39.0 \pm 3.53$ \\
EC2 & $47.9 \pm 2.64$ & $0.13 \pm 0.03$ & $37.0 \pm 2.89$ \\
EC3 & $75.3 \pm 2.89$ & $0.13 \pm 0.25$ & $44.8 \pm 3.09$ \\
EC4 & $49.6 \pm 3.23$ & $0.18 \pm 0.03$ & $32.9 \pm 2.71$ \\
EC5 & $73.3 \pm 3.09$ & $0.17 \pm 0.26$ & $48.4 \pm 2.43$ \\
EC6 & $71.4 \pm 3.04$ & $0.14 \pm 0.03$ & $58.9 \pm 2.37$ \\
Avg. & $68.5 \pm 5.29$ & $0.14 \pm 0.06$ & $43.5 \pm 3.78$ \\
Min. & $47.9 \pm 2.64$ & $0.12 \pm 0.03$ & $32.9 \pm 2.71$ \\
Max. & $88.1 \pm 4.01$ & $0.18 \pm 0.03$ & $58.9 \pm 2.37$ \\
\hline FC:Prop & & \\
\hline
\end{tabular}

FC: Propolis collected from top of deep supper the hives.

EC: Propolis collected from entrance of the hives.

All analysis were performed three times.

TPC (mg GAE/g propolis extract).

DPPH (IC $50 \mathrm{mg} / \mathrm{mL}$ ) and FRAP (mg TE/g propolis extract) of propolis collected from FC and EC. \pm standart error of mean.

\section{Total Phenolic Content (TPC)}

Total phenolic content was illustrated with gallic acid equivalency (GAE). The average of the total phenolic content of propolis EC and FC collected are 68.5 and $62.6 \mathrm{mg} \mathrm{GAE} / \mathrm{g}$ propolis extract respectively (Table 1). There appears to be no previous research exploring about comparison propolis collected from EC and FC. Socha, Galkowska, Bugaj, and Juszczak, (2015) indicate that the total phenolic content of propolis range from 150.05 to $197.14 \mathrm{mg} \mathrm{GAE} / \mathrm{g}$ propolis extract which are higher than our total phenolic content. The possible explanation is that Socha et al. (2015) collect propolis from Polland, but we collected our propolis from Turkey Black Sea region. Aliyazıcıoglu, Sahin, Erturk, Ulusoy, and Kolayli, (2013) study show that the phenolic content of the propolis collected from different part of Turkey is between 115 and $210 \mathrm{mg} \mathrm{GAE} / \mathrm{g}$. The potential explanation of these differences is that propolis collected region. Propolis collected from Black Sea region in this study, but in Aliyazıcıoglu et al. (2013) study propolis collected from different parts of Turkey. Also, different honey bees subspecies can be caused by this difference because it is well known that different honey bee species collect propolis from different propolis sources (Silici \& Kutluca, 2005).

\section{Ferric Reducing Ability of Plasma Analysis (FRAP)}

Trolox equivalent (TE) value of FRAP analysis show the concentration of antioxidant compounds. Average FRAP value was 156.59 mg TE in Ozdal, Sari-Kaplan, Mutlu-Altundag, Boyacioglu, and Capanoglu (2018) study which samples collected from different regions of Turkey. Barlak, Değer, Ucar, and Çakıroğlu (2015) calculated average FRAP value as $59.5 \mathrm{mg}$ TE in a similar work. Regional differences and use of different honey bee species may be caused these FRAP value differences. Ahmed et al. (2017) research indicate that FRAP value of propolis is calculated $62.5 \mathrm{TE} / \mathrm{g}$ that is compatible with our findings.

\section{Conclusion}

In this study, it is hypothesized that honey bees can behave selectively at propolis collection for different purposes in hives. Antioxidant activity of propolis collected from different zones of hives could be different due to this selective behaviour. However, there are no differences at antioxidant values of propolis collected from different zones. Similar future works from different areas which are rich for plant sources and contain additional analysis such as volatile compounds 
composition and phenolic composition have potential for exploring differences at propolis samples collected for particular purposes.

\section{References}

Ahmed, R., Tanvir, E. M., Hossen, M., Afroz, R., Ahmmed, I., Rumpa, N.E., Sudip, P., Siew, H.G., Siti, A.S., \& Khalil, M. (2017). Antioxidant properties and cardioprotective mechanism of Malaysian propolis in rats. EvidenceBased Complementary and Alternative Medicine, 5370545.

Aliyazıcıoglu, R., Sahin, H., Erturk, O., Ulusoy, E., \& Kolayli, S. (2013). Properties of phenolic composition and biological activity of propolis from Turkey. International Journal of Food Properties, 16(2), 277-287.

Bankova, V., Christov, R., Kujumgiev, A., Marcucci, M.C., \& Popov, S. (1995). Chemical composition and antibacterial activity of Brazilian propolis. Zeitschrift für Naturforschung C, 50(3-4), 167-172.

Barlak, Y., Değer, O., Ucar, M., \& Çakıroğlu, T. N. (2015). Effects of Turkish propolis extract on secretion of polymorphonuclear elastase following respiratory burst. Turkish Journal of Biology, 39(2), 194-201.

Bonvehí, J.S., \& Coll, F.V. (1994). The composition, active components and bacteriostatic activity of propolis in dietetics. Journal of the American Oil Chemists' Society, 71(5), 529-532.

Elmastas, M., Isildak, O., Turkekul, I., \& Temur, N. (2007). Determination of antioxidant activity and antioxidant compounds in wild edible mushrooms. Journal of Food Composition and Analysis, 20(3-4), 337-345.

Ghisalberti, E. L. (1979). Propolis: a review. Bee World, 60 (2), 59-84.

Gonzalez, R., Remirez, D., Rodriguez, S., Gonzalez, A., Ancheta, O., Merino, N., \& Pascual, C. (1994). Hepatoprotective effects of propolis extract on paracetamol-induced liver damage in mice. Phytotherapy Research, 8(4), 229-232.

Greenaway, W., Scaysbrook, T., \& Whatley, F.R. (1990). The composition and plant origins of propolis: a report of work at Oxford. Bee World, 71(3), 107-118.

Gülçin, İ., Şat, i. G., Beydemir, Ş., Elmastaş, M., \& Küfrevioğlu, Ö. ì. (2004). Comparison of antioxidant activity of clove (Eugenia caryophylata Thunb) buds and lavender (Lavandula stoechas L.). Food Chemistry, 87(3), 393-400.

Krol, W., Scheller, S., Czuba, Z., Matsuno, T., Zydowicz, G., Shani, J., \& Mos, M. (1996). Inhibition of neutrophils' chemiluminescence by ethanol extract of propolis (EEP) and its phenolic components. Journal of Ethnopharmacology, 55(1), 19-25.

Lachman, J., Orsák, M., Hejtmánková, A., \& Kovářová, E. (2010). Evaluation of antioxidant activity and total phenolics of selected Czech honeys. LWT - Food Science and Technology, 43(1), 52-58.

Marcucci, M. C. (1995). Propolis: chemical composition, biological properties and therapeutic activity. Apidologie, 26(2), 83-99.
Marghitas, L. A., Dezmirean, D., Moise, A., Mihai, C., \& Laslo, L. (2009). DPPH Method for evaluation of propolis antioxidant activity. Bulletin of University of Agricultural Sciences and Veterinary Medicine Cluj-Napoca. Animal Science and Biotechnologies, 66(1-2).

Matsushige, K., Kusumoto, I. T., Yamamoto, Y., Kadota, S., \& Namba, T. (1995). Quality evaluation of propolis 1. A comparative study on radical scavenging effects of propolis and vespae nidus. Journal of Traditional Medicine, 12, 45-53.

Mercan, N., Kivrak, I., Duru, M. E., Katircioglu, H., Gulcan, S., Malci, S., ... \& Salih, B. (2006). Chemical composition effects onto antimicrobial and antioxidant activities of propolis collected from different regions of Turkey. Annals of Microbiology, 56(4), 373.

Mitamura, T., Matsuno, T., Sakamoto, S., Maemura, M., Kudo, H., Suzuki, S., ... \& Nagasawa, H. (1996). Effects of a new clerodane diterpenoid isolated from propolis on chemically induced skin tumors in mice. Anticancer Research, 16(5A), 2669-2672.

Oyaizu. M. (1986). Studies on product of browning reaction prepared from glucose amine. Japanese Journal of Nutrition, 44, 307-315.

Ozdal, T., Sari-Kaplan, G., Mutlu-Altundag, E., Boyacioglu, D., \& Capanoglu, E. (2018). Evaluation of Turkish propolis for its chemical composition, antioxidant capacity, antiproliferative effect on several human breast cancer cell lines and proliferative effect on fibroblasts and mouse mesenchymal stem cell line. Journal of Apicultural Research, 57(5), 627-638.

Popova, M., Antonova, D., \& Bankova, V. (2017). Chemical composition of propolis and American foulbrood: Is there any relationship? Bulgarian Chemical Communications, 49, 171-175.

Shimada, K., Fujikawa, K., Yahara, K., \& Nakamura, T. (1992). Antioxidative properties of xanthan on the autoxidation of soybean oil in cyclodextrin emulsion. Journal of Agricultural and Food Chemistry, 40(6), 945-948.

Silici, S., \& Kutluca, S. (2005). Chemical composition and antibacterial activity of propolis collected by three different races of honeybees in the same region. Journal of Ethnopharmacology, 99(1), 69-73.

Slinkard, K., \& Singleton, V. L. (1977). Total phenol analysis: automation and comparison with manual methods. American Journal of Enology and Viticulture, 28(1), 4955.

Socha, R., Gałkowska, D., Bugaj, M., \& Juszczak, L. (2015). Phenolic composition and antioxidant activity of propolis from various regions of Poland. Natural Product Research, 29(5), 416-422.

Talla, E., Tamfu, A.N., Gade, I.S., Yanda, L., Mbafor, J.T., Laurent, S., Luce, V.E., Milena, P., \& Bankova, V. (2017). New mono-ether of glycerol and triterpenes with DPPH radical scavenging activity from Cameroonian propolis. Natural Product Research, 31(12), 1379-1389. 